\title{
9
}

\section{The Development of Computer Assisted School Administration in New Zealand: A Case Study}

\author{
C.J. Patrick Nolan \\ Educational Research and Development Centre, Massey University, Palmerston \\ North, New Zealand
}

\begin{abstract}
This paper reports the development of computer assisted school administration (CASA) in New Zealand as a case study based on the Massey University School Administration by Computer Project, commonly known as MUSAC. Over five years, MUSAC software has been acquired by $67 \%$ of all New Zealand schools either using, or likely to use, computers for administrative purposes. The Study is in four sections which: outline the grass roots form that CASA development in general has taken; describe the New Zealand school system in terms of its role as a market; tell the story of MUSAC in terms of its origins, development strategies and attributes of the software; analyse and interpret the MUSAC software acquisition and use patterns of schools using educational management and administration (EMA) concepts; and conclude with a summary of the findings and discussion of implications for ongoing research and development.
\end{abstract}

Keyword Codes: H.4.1; K.3.1

Keywords: School Administration; Educational Management; Computers; Information Technology.

\section{INTRODUCTION}

New Zealand school administration software appears similar in both structure and content to that found in other school systems e.g. OASIS software used by NSW Schools in Australia [1]. The New Zealand approach to software development and to its adoption and use by schools seems, however, to be markedly different for two reasons. Firstly, the New Zealand Government has, from the early 1980s, maintained a policy of non- involvement. It does not play a role in the development of software and it does not fund schools to purchase hardware and software for administrative purposes. Secondly, and partly in response to the Government policy of noninvolvement, grassroots initiatives in New Zealand have independently provided schools with the administrative software solutions and strategies they require.

One particular initiative, The Massey University School Administration by Computer project (known throughout New Zealand schools as MUSAC) epitomises this grassroots development. Since establishment in 1989, MUSAC software has been acquired by $67 \%^{1}$ of all New Zealand schools either using computers, or likely to use them, in support of school management and administration. Moreover, at a point when nationwide research (e.g. surveys of software acquisition and use patterns) has not yet been carried out, MUSAC records contain the only systematically

1. Since data analysis in March 1994, the number of MUSAC using schools has increased to over $70 \%$. 
collected data on this topic. Arguably, the records provide the best available data required to gauge the extent of computer assisted school administration for the country as a whole.

\subsection{Purpose}

Accordingly, this Paper reports the development of computer assisted school administration (CASA) in New Zealand as a case study based on MUSAC. The Study is in sections covering: the general grass roots form that CASA development has taken; the New Zealand school system in terms of its role as a market; the story of MUSAC in terms of its origins, development strategies and attributes of the software; analysis and interpretation of MUSAC software acquisition and use patterns of schools, using educational management and administration (EMA) concepts; and conclusions which summarise the findings and examine implications for ongoing research and development of CASA.

\subsection{Position}

The position taken is that research is a key step necessary in helping schools to: (i) better understand ways that computer technology might be used to enhance school management and administration; and (ii) fully exploit the capability of information technology as an educational management and administration resource. Contemporary experience [4] generally, and the experience of MUSAC in particular, shows that success in this enterprise depends on end users, developers and researchers working collaboratively. The "grassroots" development of this relationship is the underlying theme of the Paper.

\section{THE DEVELOPMENT OF CASA IN NEW ZEALAND}

As in other countries [6], teacher enthusiasts, with computer programming skills, pioneered the development of CASA in New Zealand during the late 1970s. Generally, they defined their mission as developing programs to help school administrators economise on the use of their time, i.e. be more efficient. Thus, programs were developed to deal with such recurring, but key, administrative tasks as scheduling, pupil registration, school accounting and marks analysis. In some instances, the developers formed school-based businesses and generated revenue for their schools. For example, MUSAC software was initially developed in this way. Others left teaching and formed small school software businesses and marketed their products to schools in the local region.

CASA development, thus initiated [5], was largely uncoordinated and ad hoc in character, resulting in a diversity of functional, integrated and single purpose software solutions and strategies. Designed by teachers and school administrators who understood schools and how they worked, the solutions tended to be well received because they met administrative and management needs as defined by the schools themselves. As the principal developer of MUSAC once commented: "Our first priority was to develop computerised methods and procedures that would help schools become masters of their own destinies and managers of their own affairs".

From around the mid-1980s, commercial organisations such as banks, accountancy firms and business software houses entered the field. Not infrequently, they sold business software to schools straight off the shelf. Government restructuring of the education system and the mandating of individual schools to manage themselves in the late 1980s quickened schools' interest in the use of computers. More often than not, this was because they saw computers as a means of rendering school administration more efficient and effective at a time when the work loads of administrators and teachers alike seemed to be increasing dramatically. 
In Visscher's [5] terms, this was a time of transition from the stage of initiation to a stage of expansion as both the business community and the schools themselves began to recognise more clearly, though from somewhat different perspectives, the potential of computers to support school administration. On the whole, the school software businesses seem to have been more successful than the commercial organisations for two reasons: (i) they understood better than the commercial organisations the distinctive data and information processing requirements of schools; and (ii) they designed special purpose applications capable of doing what the schools wanted. The more advanced packages incorporated an integration feature with the capability to transport data between applications.

During the expansion stage, probably still in progress for a significant minority of schools, individual schools grappled with the different but related challenges of: (i) managing the computer environment in a technical sense; and (ii) understanding how the much vaunted benefits for school administration might be realised.

The accelerated rate at which schools have acquired administrative hardware and software during the late 1980s and early 1990s (e.g. 100 MUSAC-using schools in January 1989 to approximately 1300 in May 1994) would seem to indicate, in terms of the system as whole, that New Zealand schools have now effectively integrated computer technology into their day to day management and administrative practice. Judging by the MUSAC software acquisition patterns analysed later in the Paper, a great many schools from across the full spectrum of school types have, moreover, achieved a state of consolidation. That is to say, they have, in Visscher's [5] terms: (i) achieved the automation of activities goal (viz. the improvement of the efficiency of clerical activities) characteristic of initiation and expansion; and (ii) shifted attention from the management of computerisation to the management of information. As the MUSAC data also show, however, the way schools actually manage information (i.e. their use patterns) may vary across types of schools, though not across school sectors.

\subsection{The New Zealand School System}

The information in Table 1 on the school sectors and types ${ }^{2}$ of school in New Zealand, along with percentages of schools which use MUSAC software, sets the scene for the Case Study.

MUSAC-using schools (1253) taken as a fraction of all schools in New Zealand (2795), represent only $46 \%$ of the total. It is important to note, however, that few, if any, schools with five or less teachers (938 out of 2221 , i.e. $42 \%$ of all primary schools) either use computer technology for administration or can be expected to do so in the foreseeable future. In terms of their small size and limited financial resources, expenditure on in-school administrative computing is perceived as not being justified. Accordingly, schools with five or less teachers are excluded from the estimated size of the school market used in the analyses of this Paper. All schools in each of the remaining three school types (intermediate, secondary and area) are either using computers for administration or have the potential to do so. In light of these considerations, the size of the school market for computer administration software is shown in the Table as 1857 schools and MUSAC's share of this market (1253/1857) as 67\%.

2. School types in New Zealand: Primary schools consist of contributing (925) and full (1251) primaries which cater respectively for 5 to 10 year olds ( $\mathrm{K}$ to 5 ) and 5 to 12 year olds ( $\mathrm{K}$ to 7 ), ranging from single teacher schools in geographically remote areas to large urban schools with 20 or more teachers. Intermediate schools (a form of two year middle school common in the USA) cater for the education of 11 to 12 year olds in Grades 6 and 7 with students fed into them from surrounding contributing primary schools. Secondary schools may include 11 to 17 year olds (Grades 6 to 12), though typically they encompass the lesser age range from 13 to 17 (Grades 8 to 12). Area schools, typically in remote areas where only one school is justified to serve a community, encompass the full age and grade range from 5 to 17 years (K to 12 ). 
Table 1

Schools in New Zealand by Type, Sector, MUSAC Users

\begin{tabular}{lcccccc}
\hline Types & Sectors & State & Integrated & Private & Total & \multicolumn{2}{c}{ MUSAC Users } \\
\hline Primary & 1939 & 212 & 70 & 2221 & $\mathrm{~N}$ & $\%$ \\
Intermediate & $(1149)^{*}$ & $(104)$ & $(30)$ & $(1283)$ & 881 & 69 \\
Secondary & 147 & 0 & 2 & 149 & 103 & 69 \\
Area & 257 & 62 & 19 & 338 & 253 & 75 \\
\multirow{2}{*}{ Total } & 37 & 6 & 44 & 87 & 16 & 18 \\
\hline
\end{tabular}

* $(\quad)=$ adjusted totals after removal of primary schools with 5 or less teachers.

The market extends across all three school sectors. Thus, the MUSAC data base of user records makes no distinction between schools on the basis of sector identity. School type appears, however, to consist of sub-markets within the overall school market. As the analyses and interpretations which follow later in the case study show, school type is a variable which influences both the acquisition of administrative software, and, its pattern of use.

\section{THE MUSAC CASE STUDY}

The MUSAC Project was established in 1989 as a university-based, as distinct from a Government or private sector-based, initiative. Located within the Educational Research and Development Centre of Massey University, its mission is to:

create, and market to New Zealand schools, a comprehensive computerised school administration system that will enable school administrators and teachers to meet the challenge, set for them by Government, to govern themselves, direct their own development, rather than be directed from without as in the past, and become wholly responsible for making their own decisions and managing their own affairs.

Given the limited budgets within which most New Zealand schools operate and the relative paucity of their computer knowledge, three further requirements were built into the MUSAC development brief. The software must also be affordable, user friendly and robust.

\subsection{Origins}

Prior to the establishment of MUSAC, various other school administration software developed overseas (e.g. the OASIS package (1) from NSW, Australia) were considered by the University for adoption in New Zealand. The final decision to "go with a home grown solution" was taken for a number of reasons: (i) such a solution already existed; (ii) it had built into its design most, if not all, the functionality already observed in overseas systems; (iii) schools already using it reported that it worked well and they were confident that it would appeal to others; and (iv) the software design philosophy, involving such attributes as responsiveness, flexibility and inventiveness, fitted with the values of Massey University faculty who saw CASA as a means of facilitating administrative practices shown to be effective by contemporary experience and research $[3,4]$, e.g. collaborative decision making and participatory management. 
The precursor to MUSAC, called the Waiopehu Package, was developed by its teacherinventor, part-time over about five years, as an extra curricula interest, to assist one secondary school, Waiopehu College. Beginning in 1985, he adopted a developmental approach in the sense of creating two generic programs to address two general tasks commonly perceived by school administrators as central to the operation of schools as educational organisations: Pupil Files to deal with a range of data and information integral to the management of pupils; and, Accounts to deal with the financial accounting aspects of school management and administration. An integration capability was built in from the outset thus permitting the transfer of data and information between the two core programs and others that would be developed later.

Between 1985 and 1987, five new packages were added. Four were designed to complement Pupil Files and extended the range of pupil management functions amenable to treatment via computer. They included Marks Analysis in 1986 and Electronic Markbook, Absences and Timetable in 1987. School Wages was added in 1987 to complement Accounts, further extending the computerisation of school financial management functions. Thus, by the time Massey University approached the developer in 1988 and invited him to form a University-based school administration software business (given the name MUSAC in early 1989), the Waiopehu Package was an integrated suite comprised of two general purpose and five special purpose administrative programs, designed so that exisitng programs could be continuously refined to meet existing needs better and others created to anticipate new needs.

\subsection{Development plan}

The MUSAC development plan, fomulated during establishment in 1989, was based on the assumption that success would depend on the schools themselves taking ownership of the enterprise. As with the Waiopehu Package, this would require school participation, i.e. "grassroots involvement" in all phases of software design from planning, through development testing to user evaluation. Consistent with the assumption, the Plan contained a strategy comprised of three elements: (i) the welcoming of flexibility and divergent approaches in the design of software which involves listening to, and valuing, the ideas of others in and outside of MUSAC, especially end-users; (ii) the adoption of a concept of "user friendliness" somewhat broader in scope than conventional definitions involving a user group, help desk and rewards to users for good ideas and error detection; and (iii) subscription by the software developers and customer support staff to a continuous problem-solving approach, with solutions provided by end-users being regularly incorporated into software updates.

All three of the above elements working together seem to have created an organisational culture which encourages MUSAC staff to be both responsive and anticipatory in their approach to software design. On the one hand, existing software is constantly being revised so as to better meet existing school needs, e.g. the release of Pupil Files Version 4 early in 1994. On the other hand, new software is constantly under development, anticipating changes and new developments, e.g. the introduction in 1994 of a National Qualifications Framework, whose implementation at the school level might be enhanced or, made more manageable, by the use of competent purpose designed software, e.g. a program for recording and analysing student achievement. To this end, MUSAC staff constantly update their knowledge of both technical computer developments and educational developments affecting the schools. They do this by regular attendance at training workshops and computer conferences (e.g. COMDEX in the USA) and by constantly liaising with the schools themselves and with Ministry of Education officials.

On the face of it, features of the software attributable to the MUSAC culture and its strategy may appear unremarkable. The point is, of course, that a great deal of school administration 
software, by lacking one or more of the three elements mentioned above, commits schools to maintenance of the status quo rather than to the adoption of a reflective-developmental administrative philosophy and approach. Writers such as Naisbitt have shown that the latter is essential if schools are to function effectively in the rapidly changing society of today and tomorrow.

\subsection{The MUSAC package}

By 1994, the complete MUSAC package has been developed as a fully field tested, integrated suite of 15 school data and information processing Programs ${ }^{3}$. They are organised as modules covering four generic categories of educational management and administration (EMA) functions. It is noted here, in anticipation of the analyses to come, that the acronym EMA, standing for Educational Management and Administration, is used to name two constructs, EMA Category and EMA Type, which are the two main descriptive and analysis tools of the paper. It should also be noted that EMA Type, which refers to the way combinations of programs are used in schools, differs from School Type which refers to the four categories of school in New Zealand - primary, intermediate, secondary and area schools.

In Table 2 below, the programs of the MUSAC package are located on the vertical axis against the EMA category to which they belong. EMA category 1 is subdivided into three subcategories to distinguish programs in three different, but related, aspects of the Pupil Management function, namely pupil organisation, performance and behaviour. EMA category 4 refers to User Group and Help Desk which are facilities rather than programs. It anticipates the instructional programs yet to be developed but acknowledges the role that User Group and Help Desk play in lieu of such programs. The remaining two categories, Learning Resource Management and Administration and Financial Management complete the set within which MUSAC sofware has been developed to date. Thus organised, Table 2 identifies the year in which each program was made available for school use and displays the pattern of MUSAC software acquisition across school types.

As with other school administration software, MUSAC software permits networking, thus enabling decentralised access and interaction through remote terminals. The inclusion of such a facility could be taken as a MUSAC commitment to the development of professional collegiality and collaboration. Experience and research $(3,4)$ have demonstrated that such characteristics are commonly associated with effective school administration. Ease of information sharing, made possible through computer technology, facilitates this effectiveness.

\section{ANALYSIS AND INTERPRETATION: ACQUISITION AND USE PATTERNS}

\subsection{Acquisition patterns}

Examination of Table 2 reveals that three MUSAC programs predominate. The programs are: Pupil Files - primary (76\%), intermediate (92\%), secondary $(87 \%)$, area (94\%); Accounts - primary (66\%), intermediate (71\%), secondary (65\%), area (81\%); and Resource Manager primary $(53 \%)$, intermediate $(72 \%)$, secondary $(60 \%)$, area $(94 \%)$.

The pattern is partly explained in terms of the status of Pupil Files and Accounts as the core programs of the MUSAC suite. The prior installation of Pupil Files is necessary in order to run nine other programs, namely: Modules and Exam Entries (pupil organisation); Marks Analysis, Markbook, Progress Monitor and Reports (pupil performance); and Absences and Discipline (pupil behaviour). The specific programs used reflect schools' particular priorities for information processing in the general area of pupil management. The use of Accounts and Resource Manager

3. Two new programs, Achievement Record and Financial Management, will be released to schools in 1994. 
is linked with financial accountability requirements. The requirements are pressing nowadays with New Zealand schools expected to operate as, in the words of one commentator, "viable business entities".

The high membership of User Group (not less than $90 \%$ for any school type) signifies two concerns that schools frequently express: (i) that access to back-up and support is available when required; and (ii) that the User Group will provide school staff with a form of training (self instruction using manuals and contact with the Help Desk) but that other forms of training are also required. The latter is evident in the high demand for, and attendance at, regional training seminars conducted by MUSAC staff and the proliferation of on-site training provided by 12 independent MUSAC regional support agencies which have come into existence over the past five years.

Table 2

Distribution of MUSAC Programs by EMA Category for All School Types, March 1994

\begin{tabular}{|c|c|c|c|c|c|c|c|c|c|c|c|}
\hline \multirow{2}{*}{$\frac{\text { MUSAC Programs }}{\text { EMA Category 1: Pu }}$} & \multirow{2}{*}{$\frac{\text { Dates }}{\text { ipil Man }}$} & \multicolumn{2}{|c|}{ Primary } & \multicolumn{2}{|c|}{ Intermediate } & \multicolumn{2}{|c|}{ Secondary } & \multicolumn{2}{|c|}{ Area } & \multicolumn{2}{|c|}{$\begin{array}{c}\text { Programs in } \\
\text { Use }\end{array}$} \\
\hline & & ageme & & & & & & & & & \\
\hline Organisation: & & $\mathrm{N}$ & $\%$ & $\mathrm{~N}$ & $\%$ & $\mathrm{~N}$ & $\%$ & $\mathrm{~N}$ & $\%$ & $\mathrm{~N}$ & $\%$ \\
\hline Pupil Files & 1985 & 668 & 76 & 95 & 92 & 221 & 87 & 15 & 94 & 999 & 80 \\
\hline Time Table & 1987 & 6 & $<1$ & 3 & 3 & 202 & 80 & 6 & 38 & 217 & 17 \\
\hline Modules & 1992 & 0 & 0 & 0 & 0 & 25 & 10 & 0 & 4 & 25 & 2 \\
\hline Examination Entries & 1992 & 3 & $<1$ & 0 & 0 & 137 & 54 & 1 & 6 & 141 & 11 \\
\hline \multicolumn{12}{|l|}{ Performance: } \\
\hline Marks Analysis & 1986 & 2 & $<1$ & 2 & 2 & 175 & 69 & 4 & 25 & 183 & 15 \\
\hline Electronic Markbook & 1987 & 5 & $<1$ & 6 & 6 & 177 & 70 & 3 & 19 & 191 & 15 \\
\hline Progress Monitor & 1993 & 166 & 19 & 37 & 36 & 46 & 18 & 0 & 0 & 249 & 20 \\
\hline School Reports & 1992 & 3 & $<1$ & 6 & 6 & 50 & 20 & 0 & 0 & 59 & 1 \\
\hline \multicolumn{12}{|l|}{ Behaviour: } \\
\hline Discipline & 1993 & 8 & $<1$ & 6 & 6 & 17 & 7 & 2 & 13 & 33 & 1 \\
\hline Absences & 1987 & 19 & 2 & 9 & 9 & 161 & 64 & 3 & 13 & 192 & 15 \\
\hline \multicolumn{12}{|c|}{ EMA Category 2: Learning Resource Management } \\
\hline MUSAC Library & 1991 & 212 & 24 & 42 & 41 & 83 & 33 & 6 & 38 & 343 & 27 \\
\hline Bar Codes & 1992 & 17 & 2 & 4 & 4 & 10 & 4 & 0 & 0 & 31 & 2 \\
\hline \multicolumn{12}{|c|}{ EMA Category3: Administration and Financial Management } \\
\hline MUSAC Accounts & 1985 & 585 & 66 & 73 & 71 & 163 & 65 & 13 & 81 & 834 & 67 \\
\hline Resource Manager & 1989 & 469 & 53 & 74 & 72 & 153 & 60 & 15 & 94 & 711 & 57 \\
\hline MUSAC Payroll & 1987 & 37 & 4 & 9 & 8 & 61 & 24 & 3 & 19 & 110 & 9 \\
\hline \multicolumn{12}{|c|}{ EMA Category 4: Staff Training and Support } \\
\hline \multirow[t]{2}{*}{ User Group } & 1989 & 786 & 90 & 98 & 95 & 233 & 92 & 16 & 100 & 1133 & 90 \\
\hline & OTAL & 881 & 100 & 103 & 100 & 253 & 100 & 16 & 100 & 1253 & 100 \\
\hline
\end{tabular}


The acquisition patterns for other programs reflects varying school needs for different kinds of processing capability. For instance, the relatively low acquisition rate of Library (not more than $41 \%$ of schools of any type) may be due to a number of factors: the fact that large libraries requiring search capabilities and automated borrowing methods are found mainly in secondary, area and intermediate schools and not the primaries, the classroom-based way that libraries are used in primary schools, or, simply, that the program has only been available for three years!

More specialised programs such as Timetable, Marks Analysis and Markbook, commonly found in secondary schools and to some extent in area schools, are not configured for use in primary and intermediate schools. The latter have simpler scheduling requirements (i.e. a one teacher per class pattern) and are less dependent on examinations as their main assessment procedure. The acquisition of Progress Monitor by a small but significant number of primary, intermediate and secondary schools $(19 \%, 37 \%$ and $18 \%$ respectively) reflects the importance that these schools attach to teachers maintaining high quality, regularly updated, records of student progress but minimising the time required to do this task.

\subsection{Use patterns}

For the purposes of analysis, it is assumed that the greater the number of programs and the combinations of categories of programs acquired by any given school, then the greater the likelihood that the programs are actually being used. In days gone by, the fact that a school had acquired new technology was no guarantee that this was the case. For instance, teaching machines of the 1960s were typically put in a cupboard at the back of the classroom and left to gather dust [2].

Three sources of information, however, support the assumption: once schools have acquired a first MUSAC package, and presumably mastered it, they tend to acquire further packages; there is a steady increase in the rate of acquisition, approximately $20 \%$ per annum; and the continuing heavy membership of User Group and extensive use of the Help Desk indicates that the programs are being used and not just "left sitting on the shelf".

\subsection{Method}

Data contained in the MUSAC data base of user records is in the form of strings of letters standing for the MUSAC programs used by each school, e.g. a three item string, 'gpu' stands for Progress Monitor, Pupil Files and User Group. The greater the number of items in each string, the greater the number of program combinations likely to be found in a school. The following three step procedure, using the EMA concepts referred to earlier, was devised to convert the data strings into a form suitable for analysis.

Step 1 - involved sorting the primary data (i.e. programs) from the MUSAC records into 1,253 coded strings of letters, one string for each school, with strings ranging from one to 15 items and each letter standing for a particular program e.g. 'a' = Accounts, 'p' = Pupil Files 'u' = User Group.

Step 2 - involved recoding the strings according to the EMA category from Table 2 to which each program belongs (viz. P=Pupil Management; L=Learning Resource Management; $\mathbf{A}=$ Administration and Financial Management; and $\mathbf{T}=$ Staff Training and Support) to produce a shorter EMA category string. The three examples below illustrate this step:

(i) a single item string such as the program, ' $\mathrm{g}$ ' (Progress Monitor) would be coded ' $\mathrm{P}$ ' because it is in the Pupil Management category; 
(ii) a three item string, 'gpu' (Progress Monitor, Pupil Files and User Group) would be coded 'PT', i.e. a Pupil Management and Staff Training category combination; and

(iii) a five item string, 'alpru' (Accounts, Library, Pupil Files, Resource Manager and User Group) would be coded 'PLAT' which covers all four EMA categories.

Step 3 - involved entry of the recoded data from Step 2 into Matrices, one matrix for each school type, with EMA Types located on the $\mathrm{Y}$-axis and 'Number of programs per school' ( 1 to 15 ) located on the ' $\mathrm{X}$-axis. An EMA Type refers to the ways in which the strings of programs actually used in schools fall into particular EMA category combinations.

Because there are only four EMA categories, there can be only four EMA Types. Each is operationally defined below in terms of its constituent EMA category combinations:

EMA Type 1 - P, L, A, or T for schools using MUSAC programs in one EMA category;

EMA Type 2 - PL, PA, PT, LT, LA or AT for schools schools using MUSAC programs in two EMA categories;

EMA Type 3 - PAL, PAT, PLT or ALT for schools using MUSAC programs in three EMA categories; and

EMA Type 4 - PLAT for schools using MUSAC programs in all four EMA categories.

Schools in EMA Type 1 may be using as little as one MUSAC program and as many as 10, e.g. all the programs which belong to $\mathrm{P}$, the Pupil Management category. An EMA Type 4 school cannot use less than four programs, i.e. one from each category, but may use up to fifteen i.e. all the MUSAC programs. Thus, four programs per school is the threshold across which any given school must pass in order to support a full range of EMA functions by computer.

\subsection{EMA Type analyses}

Examination of the distribution of "programs per school' sets the scene for the EMA Type analyses which follow. Table 3 presents the relevant data in rows for each school type and split columns containing: (i) the 
number of schools which has acquired a given number of programs (1 to 15) expressed as a percentage (\%); and (ii) the cumulative percentage of schools (C\%) which has acquired up to a given number of programs, beginning with $100 \%$ in column 1 and decreasing to $0 \%$, e.g. $92 \%$ of primary schools use up-to 2 programs but no primary school is using 8 or more programs.

From the cumulative percentages in Table 3 , it can be seen that marked differences exist between school types at the threshold point (column $4: 45 \%, 68 \%, 59 \%$ and $83 \%$ respectively for primary, intermediate, area and secondary schools). By column 7 , the differences are of almost geometric proportions at $1 \%, 9 \%, 18 \%$ and $65 \%$ respectively.

Diagram 1: Cummulative \% of Programs per School Across School Types

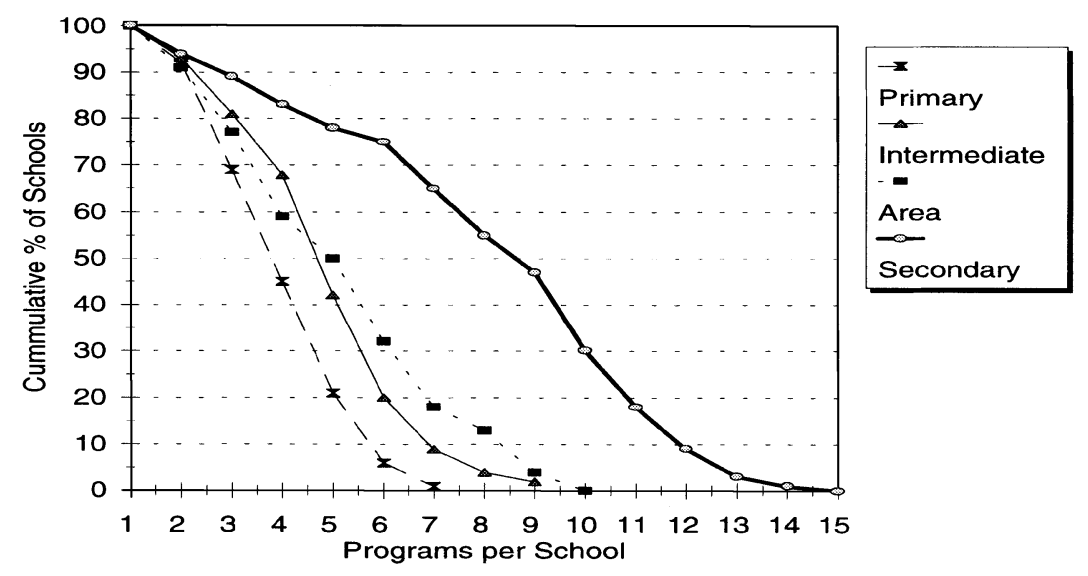

Diagram 2: Distribution of Programs Per School for Each School Type

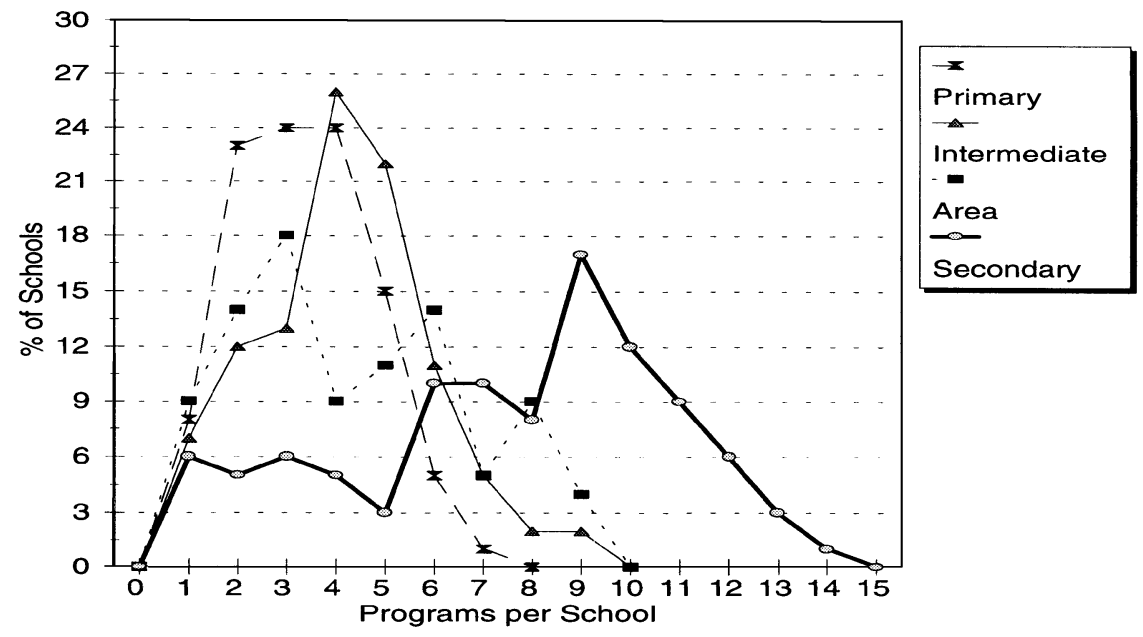


Graphical representation of the cumulative data in Diagram 1 and graphs of the distribution of programs across school types in Diagram 2 further illustrates the differences. One interpretation is that secondary schools have achieved a much wider range of uses than the other three school types simply because they possess more programs.

The EMA Type analyses which follow next test this conclusion further by examining: (i) how the contents of the EMA Types are distributed across and within each school type; and (ii) how the EMA Types themselves are distributed across "programs per school" for each school type.

\subsection{The contents of EMA Type across School Types}

Pie diagrams displaying distribution data, presented together in Diagram 3, permit comparative contents analysis across school types for each EMA type. While the EMA categories P and A predominate across all four school types for EMA Type 1, there are variations in the percentage distributions which require comment.

Primary schools have probably acquired financial management software $(A=58 \%)$ as their first priority for two reasons: they are learning how to function as an "educational business" and see such software as a good way to achieve this end; or use of the software enables them to manage their financial affairs more cheaply than hiring an agency to do the job, thus freeing up money for other resources. For secondary schools, more accustomed to managing themselves financially than primary schools, it is likely that Pupil Management takes priority (thus $\mathrm{P}=63 \%$ ). With intermediate schools, which fall between primary and secondary in the sense of combining attributes from both, it seems not too surprising that programs belonging to $\mathrm{P}$ and $\mathrm{A}$ have been acquired in equal numbers, viz. $43 \%$. Area schools tend to have a small secondary department with the bulk of pupils at the primary level, perhaps accounting for the preponderance of category ' $A$ ' (100\%) in EMA Type 1. With regard to the total absence of EMA category $T$ and the relative absence of L, it may seem like stating the obvious but none the less it is worth noting that schools of any type are highly unlikely to: (i) seek training before they have acquired a program; and (ii) acquire a Learning Resource Management program in preference to say a Pupil or Financial Management program, when they are contemplating "getting into CASA". Two exceptions have been noted: some schools have acquired Library software (EMA category L) while using another software package for pupil management and/or administration and financial management; and some schools use an external agency to assist with the management of school finances.

Of the six EMA category combinations of EMA Type 2, the predominance of 'PT' and 'AT' is evident across all but one school type: primary - $\mathrm{AT}=46 \%$ and $\mathrm{PT}=43 \%$; secondary - $\mathrm{AT}=$ $11 \%$ and $\mathrm{PT}=77 \%$; and area $-\mathrm{AT}=67 \%$ and $\mathrm{PT}=33 \%$; with intermediates the exception $-\mathrm{PT}$ $=63 \%$ and $\mathrm{LT}=37 \%$. An explanation is that schools in EMA Type 2 have embarked on CASA by electing to acquire and use one program upon commencement, supported by User Group membership and staff training. One measure of the success of their endeavours might be the future acquisition of additional programs in a different EMA category!

Of the four possible category combinations of EMA Type 3, the 'PAT' combination dominates: primary - $89 \%$; intermediate - $92 \%$; secondary - $91 \%$; and area - $100 \%$. This pattern seems to represent a kind of convergent evolution at the EMA Type 3 level. In Visscher's (5) terms, it might be interpreted as a form of consolidation forming the basis for ongoing CASA development at the EMA Type 4 level.

With 'PLAT' being the only combination in EMA Type 4, the percentage of schools operating in this Type indicates the extent to which the use threshold referred to earlier has been passed: Primary $=15 \%$; Intermediate $=35 \%$; Secondary $=27 \%$; and Area $=26 \%$. The pattern seems 


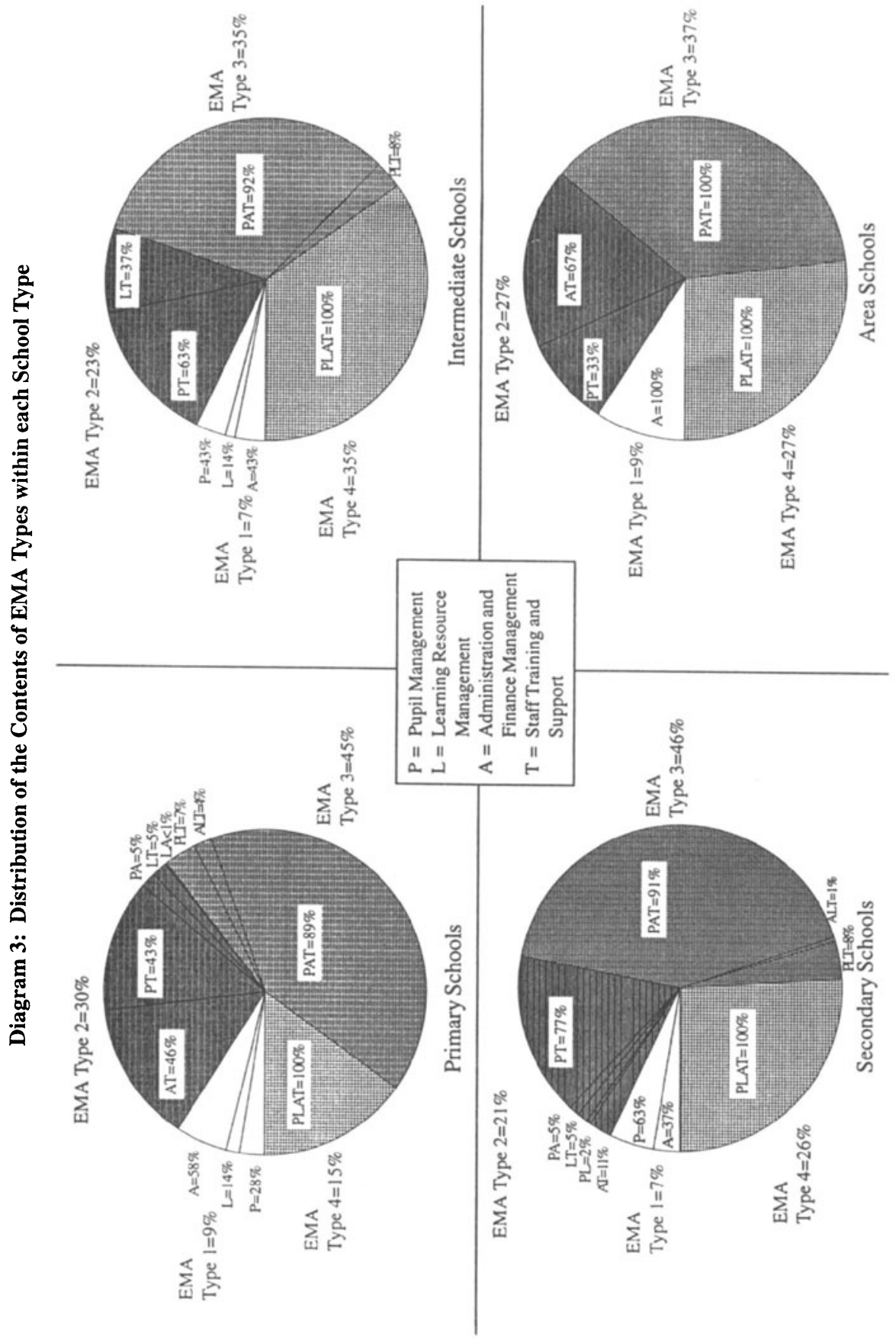


paradoxical in that the secondary school type, with by far the greatest spread of programs, has fewer schools than might have been expected in EMA Type 4 while intermediates have more than expected. An attempt at explanation is made shortly when examining the distribution of EMA Types by 'programs per school'.

For the moment, the distribution patterns in the pie diagrams indicate the importance that schools of all types attach to the acquisition, and use, of combinations of $\mathrm{P}, \mathrm{A}$ and $\mathrm{T}$ category programs. Indeed, it seems that the dominant progression is:

(i) acquisition, mastery and use of programs in EMA categories ' $\mathrm{A}$ ' and ' $\mathrm{P}$ ' first;

(ii) add Staff Training, category ' $\mathrm{T}$ ' to ensure that mastery is achieved, which means that EMA Type 2 combinations 'PT' and 'AT' predominate (either initially or as the second step in program acquisition and use); and

(iii) precede to EMA Types 3 and 4, but with the EMA Type 3, 'PAT' combination of categories dominant as the basis for expanding the scope of CASA development.

\subsection{Distribution of EMA Types across "programs per school"}

The area charts, presented together in Diagram 4, enable comparisons of the way EMA Types are distributed across programs per school.

Although any given school in an EMA Type 1 could be using up to 10 programs, most schools in this EMA type use only one program, even the secondary schools. Similarly with EMA Type 2, most schools in this Type have only two to three programs. Secondary schools are an exception. Here, the number of programs per school is bi-modally distributed: $10 \%$ of schools in EMA Type 2 with 2-4 programs and between $10-11 \%$ with 6-10 programs.

Of the schools using just two to three programs, one program is highly likely to be User Group (EMA category T), thus reducing the range of programs actually in use down to 1 or 2 for most schools in EMA Type 2: 30\%,23\%, 10\% and 27\% respectively across primary, intermediate, secondary and area school types.

These figures suggest that the percentages for EMA Types 1 and 2 should be combined so as to reflect what amounts to a relatively limited use of administrative software by a fairly large minority of schools from all four school types: primary $=40 \%$; intermediate $=30 \%$; secondary $=$ $18 \%$ down from $28 \%$; and area $=36 \%$. That is to say, more than a quarter of all primary, intermediate and area schools have a relatively restricted use pattern across EMA types 1 and 2. In each case, there is scope for further development with CASA.

The general pattern for EMA Type 3 indicates a solid core of schools across all school types with an apparently more extensive use of administrative programs: primary $=45 \%$ with $3-7$ programs $/$ school; intermediate $=35 \%$ with $3-6$ programs $/$ school; secondary $=46 \%$ with $3-13$ programs $/$ school; and area $=37 \%$ with 3-8 programs $/$ school.

At the EMA Type 4 end of the spectrum, differences between school types become accentuated, signified by the changing shape of the area graphs. The relatively flat secondary graphs and elongated intermediate, and to a lesser extent primary and area school graphs suggests a different kind of use pattern, signalled earlier but not explained by the cumulative percentages in Table 3 and the line graphs in Diagram 1.

The pattern is best illustrated and best understood by a comparison of intermediate and secondary schools across EMA Types 3 and 4 . The fact that $70 \%$ of all intermediate schools fall in these two types (35\% in each Type, with $10 \%$ and $9 \%$ more respectively than secondary and area schools in EMA Type 4), but use only 4 to 9 programs, indicates a policy of supporting the 
Diagram 4: Percentage of Schools by Programs per School for Each School Type

Primary Schools

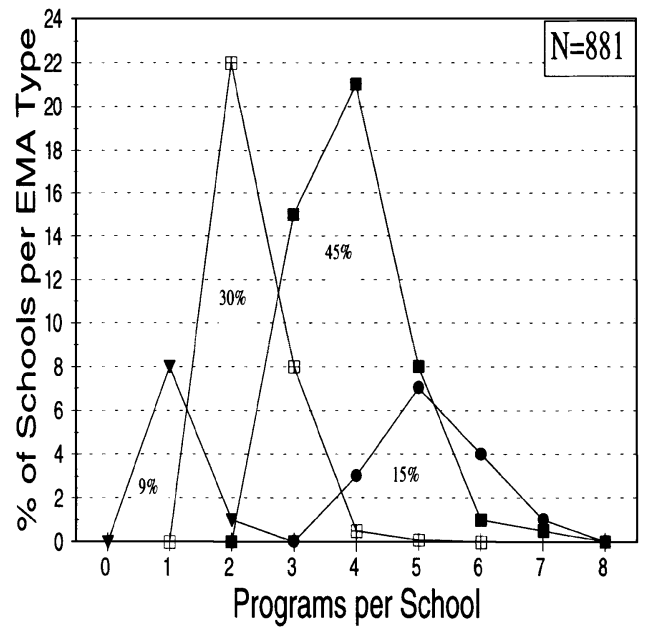

マ Type 1 世 Type 2 - Type 3 —- Type 4

Secondary Schools

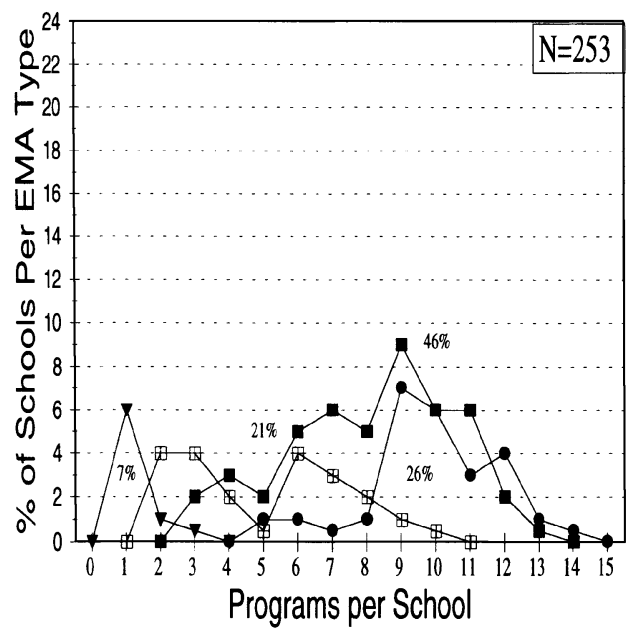

— Type 1 - Type $2-$ - Type $3-$ - Type 4
Intermediate Schools

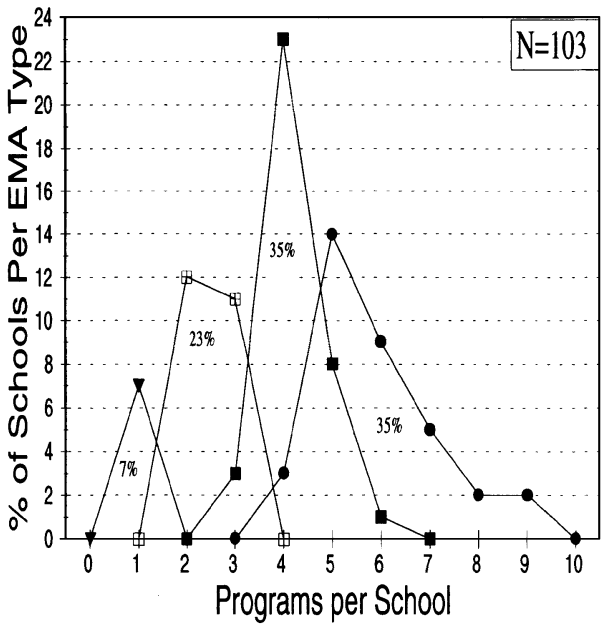

$\neg$ Type 1 - Type 2 - Type 3 - Type 4

Area Schools

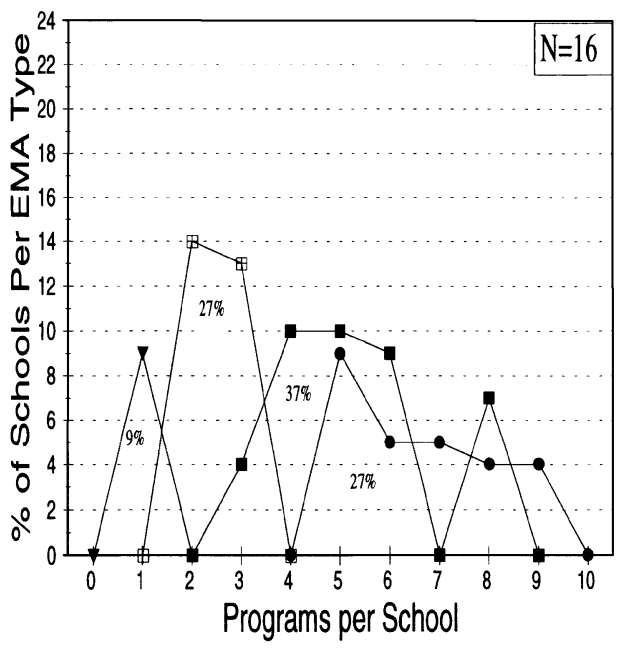

$\boxplus$ Type $1 \multimap$ Type $2 \div-$ Type $3 \bullet$ Type 4 
full range of management and administration functions but with only a core of 1 to 2 programs for each function. In contrast, the fact that $72 \%$ of secondary schools in EMA Types 3 and 4 (with $46 \%$ in EMA Type 3) use between 5 and 14 programs suggests a policy of in-depth specialist use across a narrower band of management and administration functions. Perhaps these specific differences reflect a larger difference between an integrated-holistic approach to school management and administration at the intermediate level versus a compartmentalised-functional approach at the secondary level.

Overall, the relatively large percentages of schools from all four school types falling into EMA Types 3 and 4 (primary $=60 \%$; intermediate $=70 \%$; secondary $=72 \%$ and area $=64 \%$ ), indicates that computer assisted school administration is well established in the New Zealand school system.

\section{CONCLUSIONS}

In summary, the findings indicate that the majority of MUSAC-using schools could be classified as "adult to mature users" of educational management and administration (EMA) software, although a significant minority across all school types is still at a neophyte stage. Within MUSAC-using schools as a whole, differences in use patterns may reflect different administrative requirements and different styles between school types as much as it does levels of sophistication in the use of specific programs. The differences warrant further investigation in order to better understand, and control, the direction and dynamics of computer assisted school administration in New Zealand. Such investigation might be in the form of a national survey to establish what software is actually being used in schools, case studies to record exemplary CASA practices and qualitative studies to document the level and nature of administrative software use. To this end, the approach to research presented here using EMA concepts might be of value in conducting further, perhaps more in-depth, comparative analysis of use patterns between school types.

Research into levels of use seems a logical next step in order to paint a fuller picture of the manner in which schools are using computer technology in support of school management and administration functions. Anecdotal feedback from the MUSAC Help Desk, MUSAC training seminars and school administrators doing post-graduate work, suggests that there is considerable variation in levels of use. For example, while quite a lot of secondary schools use administrative software to carry out higher order management functions (e.g. strategic planning), an equal number use it simply to generate timetables and class lists and issue parents with school accounts. Interestingly, a small but significant number of primary and intermediate schools use their somewhat fewer computer resources to make key data about the school (e.g. details of the school budget) available to the whole staff as the basis for collaborative problem solving and shared decision making. This approach appears not to be well understood in secondary schools and is, therefore, seldom used.

In the past, school inspectors and the school advisory service played a role disseminating good ideas and effective educational and administrative practices. In New Zealand's school system today, this role is now performed by periodic Ministry of Education school development contracts, delivered by various professional agencies and organisations in the community. Such contracts, if let in the general area of computer assisted school administration, could build upon the findings of this and subsequent research by funding programmes within which knowledgeable and experienced educational practitioners might help less experienced schools avoid pitfalls and pursue beneficial development paths. This could be an effective means of demonstrating how information sharing and collaboration between schools (as distinct from insularity and isolation) empower schools to get the best value from their administrative computing resources. 
Irrespective of what happens, MUSAC will continue to play a dominant role as New Zealand's only university-based enterprise providing affordable, competent and user-friendly administration software that New Zealand schools require. The location of MUSAC in a university provides the software developers with three specific freedoms apparently important to the success of the enterprise: (i) freedom to exercise control over (and accept responsibility for) the manner and direction in which school administration software is designed; (ii) freedom to promote educational interests by adopting a "school-centred" approach which places control over school management in the hands of school personnel; and (iii) freedom to exercise discretion in deciding from whom advice and support might be sought (e.g. schools, government, business) and ultimately accepted or rejected.

The exercise of these freedoms entails that the developers pursue their objectives in a way that is consistent with knowledge creation and research values which define the mission of a university and set it apart from the institutions and organisations of government and business. On the one hand the developer's role is to produce software that is technically competent. They are well placed to do this in the University through having ready access to the latest technical knowledge. On the other hand, their role is to encourage innovative school management by designing school administration software which incorporates the latest ideas from educational management theory and research. In respect to this aspect of the role, MUSAC staff are able to interact, and exchange ideas, with Education Faculty members and Educational Research and Development Centre staff actively working in the field of educational management and administration theory and research.

In terms of its distinctive character as a "grass roots" enterprise, MUSAC offers an alternative to the way in which computer assisted school administration has been developed elsewhere. No claim is being made here that one approach is better than another. It is important to note, however, that the combination of being university-based and "grass roots" predisposes MUSAC to be flexible, proactive and responsive. These attributes may be more difficult to achieve in school systems which have adopted a top-down, centralised approach. The former permits software designers to meet the needs of schools as their first priority. Importantly, it also leaves them free to incorporate features which enable schools to meet the requirements of external authorities, e.g. the Ministry of Education, which specify the broad parameters within which schools are mandated to educate the youth of the Nation.

\section{REFERENCES}

1. Dale, D.M. and Habib, A.G. (1991). Administrative Computing in the Australian Educational System. Journal of Research on Computing in Education, 24(1), 120-145.

2. Heinich, R., Molenda, M and Russel, J. (1990) Instructional Media and the New Technologies of Instruction, New York: McMillan.

3. Sergiovanni, T.J. (1991). The Reflective Principal, New York: Allen And Unwin.

4. Stewart, D. and Prebble, T. (1994). The Reflective Principal: School Development in a Learning Community, Palmerston North, New Zealand: ERDC Press.

5. Visscher, A. (1991). School Administrative Computing: A Framework for Analysis. Journal of Research on Computing in Education, 24(1), 1-19.

6. Visscher, A. and Spuck, D.W. (1991). Computer Assisted School Administration and Management: The State of the Art in Seven Nations. Journal of Research on Computing in Education, 24(1), 146-168. 